\title{
Succession on marine hard substrata: the adaptive significance of solitary and colonial strategies in temperate fouling communities*
}

\author{
Charles H. Greene, Amy Schoener and Elaine Corets
}

School of Oceanography, University of Washington, Seattle, Washington 98195, USA

\begin{abstract}
Community development is analysed in 7 temperate fouling communities in Puget Sound, Washington, USA. In contrast to previous investigations of succession on marine hard substrata, solitary animals dominated the available primary space in these communities at the expense of their colonial counterparts. A series of testable hypotheses are proposed to explain these findings in light of previous predictions, current successional theory and results from other investigations of temperate fouling communities. The hypothesis that we favor at present involves an inhibition-type successional process, one which leads to a community composed of species that are longer-lived or that exhibit strong selfreplacement tendencies. In Puget Sound fouling communities, many of the major solitary species are characterized by such features, and this may account for their eventual dominance. The question of whether solitary or colonial animals dominate temperate fouling communities remains unanswered and is in need of further investigation before the full evolutionary and biogeographical implications can be resolved.
\end{abstract}

\section{INTRODUCTION}

In a series of recent papers, Jackson (1977, 1979a), Buss (1979a), and Woodin and Jackson (1979) have introduced the concept of functional groups in classifying epibenthic organisms on the basis of how they use and alter their environments. A functional group includes all organisms which utilize and affect their environment in an approximately similar manner (Woodin and Jackson, 1979). In environments characterized by hard substrata, the primary division of animals into functional groups can be based on body plan and functional organization, i.e. the animals can be either solitary or colonial (Jackson, 1977; Woodin and Jackson, 1979). Jackson (1977) defines solitary animals as 'distinct individuals which usually are capable of performing all individual functions'. This he contrasts with colonial animals, 'in which members of the colony must be physically connected and... have common ancestry through asexual reproduction' (Boardman et al., 1973, cited in Jackson, 1977). These major divisions can be subdivided in a manner which reflects how the

\footnotetext{
- Contribution No. 1327 from the School of Oceanography, University of Washington
}

animals utilize available space; these groupings are defined in Table 1.

Classification by functional groups provides a useful approach in determining the relationship between form and function in the hard substratum epibenthos. In such communities, Sutherland (1978) has emphasized the functional roles of organisms as important determinants of community structure. If, as Woodin and Jackson (1979) claim, the results of competition on hard substrata show few obvious taxonomic patterns, then classification based on morphology may be the most appropriate method of assessing these functional roles.

In tropical, cryptic reef environments, Jackson (1977, 1979a), Buss (1979a), Buss and Jackson (1979), and Woodin and Jackson (1979) have been quite successful in applying this functional classification scheme as evidenced by the generally predictable nature of competitive interactions between members of different functional groups. Specifically, the overwhelming dominance of colonial animals in such reef environments has been documented and at least partially explained. In Jackson's (1977) scenario of events, solitary animals, employing a more opportunistic strategy, are relatively abundant in the earlier stages of succes- 
sion. As succession proceeds, however, colonial animals begin to dominate the assemblage by outcompeting their solitary counterparts. Jackson (1977) relates this ability of colonial animals to dominate in direct competitive interactions with solitary animals to basic differences in their respective life history and morphological attributes. In particular, asexual reproduction and indeterminate growth, as well as morphological features which reduce susceptibility to fouling and overgrowth, confer an apparently unbeatable combination of advantages to colonial animals. So convincing are these arguments in explaining the observed patterns in cryptic coral reef environments, that Jackson (1977) predicts their general applicability within most marine, hard substratum systems. With the exceptions of temperate communities dominated by dense assemblages of macroalgae and intertidal environments where physical stresses may limit the success of a colonial strategist, Jackson (1977) concludes that 'space-limited hard substrata for which we have adequate data are almost completely overgrown by colonial animals'.

Over the past $5 \mathrm{yr}$, we have been following the development of 7 fouling communities in the Puget Sound region of Washington state (Schoener and Greene, 1980; Schoener, 1981; Schoener and Schoener, 1981; Greene and Schoener, 1982; in prep.). In all of these communities, the succession has deviated markedly from our expectations based on Jackson's (1977) predictions. It is our intention in this paper to discuss the patterns we observed in these communities, and then to offer a series of testable, alternative hypotheses to explain these patterns.

\section{STUDY SITES AND METHODS}

The fouling communities from which we have collected data are located at 7 localities in the central and southern portions of Puget Sound near Bremerton, Manchester, Seattle, and Tacoma, Washington (Fig. 1, Table 2). The Manchester, Duwamish River, and Tacoma Waterway sites were monitored as part of a National Oceanic and Atmospheric Administration (NOAA) sponsored pollution assessment project, the Seacrest site was investigated as part of a National Science Foundation (NSF) insular biogeography study, and the Bremerton site was studied as part of an Office of Naval Research (ONR) sponsored project to analyze fouling community variability.

For all 7 study sites, textured, white formica panels $\left(412 \mathrm{~cm}^{2}\right.$ each) were used as artificial substrates. At Bremerton and Seacrest, the panels were suspended beneath floating docks at 1.0 to $1.3 \mathrm{~m}$ depth; at the other 5 localities, panels were suspended from fixed docks at $3.0 \mathrm{~m}$ below mean tide level. Percent cover for sessile species growing on the 'primary space' (Dayton, 1971) of a given panel's undersurface was estimated by a point sampling technique (Sutherland and Karlson, 1973), using 100 points randomly positioned over the panel's area. This sampling procedure is nondestructive with panels being resubmerged for further development after censusing. For a complete description of the study sites and field methods employed, the reader is referred to Schoener and Greene $(1980,1981)$ and Greene and Schoener (in prep.).

Two analytical methods have been applied to the data sets collected from all seven study sites, functional group analysis which is detailed here, and a multivariate cluster analysis which is described in Greene and Schoener (1982; in prep.). Functional group analysis involves, first, assigning epibenthic organisms to functional groups, and then following the development of these grouping through time. Using the definitions of Jackson (1979a) and Woodin and Jackson (1979) (Table 1), all macrofaunal species in the 7 fouling communities were classified by functional group. Since data were collected only for sessile species, sedentary animals were not included in the analysis. With all sessile species thus classified, ow

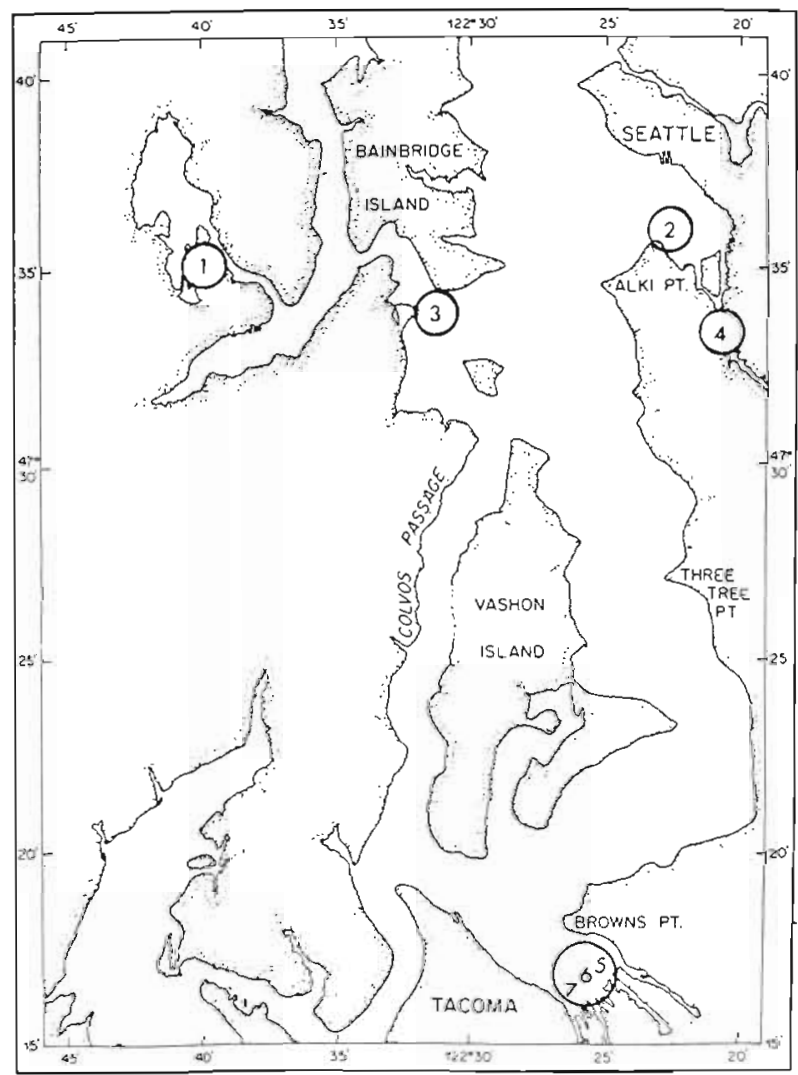

Fig. 1. Locations of the 7 study sites in Puget Sound: (1) Bremerton, (2) Seacrest, (3) Manchester, (4) Duwarnish, (5) Hylebos, (6) Blair, (7) Milwaukee 
Table 1. Functional groups for the classification of hard substratum epibenthic animals (based on Jackson, 1979, and Woodin and Jackson, 1979

\section{SOLITARY ANIMALS}

Solitary animals are subdivided into 3 groups based on mobility and life position (Woodin and Jackson, 1979):

A Sessile animals which permanently attach to the substratum after larval settlement and metamorphosis

B Sedentary animals which are capable of limited movement along the substratum surface

C Excavators which burrow into the substratum

\section{COLONIAL ANIMALS}

Colonial animals are subdivided into 6 groups based on growth form (Jackson, 1979):

A Runners which are linear or branching encrustations

B Sheets which are two-dimensional encrustations

C Mounds which are massive, three-dimensional encrustations

D Plates which are foliose projections from limited zones of substratum attachment

E Vines which are linear or branching semi-erect forms with limited zones of substratum attachment

F Trees which are erect, usually branching, projections with limited zones of substratum attachment

percent cover data were analysed for trends in the relative abundances of the various functional groups through time. The unexpected results found in our 7 time series are reported below.

\section{RESULTS}

The trends in relative abundance of solitary and colonial animals are illustrated in Fig. 2. In contrast to Jackson's (1977, Fig. 1) results from Discovery Bay,
Jamaica, free space was appropriated much more rapidly in the Puget Sound fouling communities. In addition, at all 7 of our study sites, solitary animals gradually increased in abundance through time until they eventually dominated the available primary space. This pattern, although unexpected initially, proved to be consistent despite the considerable compositional differences in fouling community development at each site (Table 3). A more detailed description of the successional patterns at the Duwamish River, Manchester, and Tacoma Waterway sites will be published elsewhere (Greene and Schoener, in prep.). Further details on the patterns observed at Seacrest and Bremerton can be found in Schoener and Schoener (1981) and Greene and Schoener (1982), respectively.

\section{DISCUSSION}

The patterns observed in Puget Sound have led us to consider 2 basic questions: first, what factors allow solitary animals to dominate eventually in these communities; second, how general a phenomenon is the dominance by solitary animals in temperate fouling communities?

\section{Success of solitary animals in Puget Sound fouling communities}

The Puget Sound fouling communities investigated possess many features in common with Connell and Slatyer's (1977) inhibition model of succession (Greene and Schoener, 1982). The basic premises of this model are that community residents tend to inhibit the invasion of subsequent colonists and suppress the growth of other resident species. Although our studies were not designed as rigorous tests of the model, our results

Table 2. General information pertaining to the study sites investigated in this paper

\begin{tabular}{|c|c|c|c|c|}
\hline Project & Study site & Location & Initiation date & Termination date \\
\hline ONR Variability & Bremerton & Phinney Bay & Jun, 1978 & Mar, 1980 \\
\hline Study & & Bremerton, WA & & \\
\hline NSF Insular & Seacrest & Elliot Bay & Jun, 1977 & May, 1979 \\
\hline Biogeography Study & & Seattle, WA & & \\
\hline NOAA Pollution & Blair & Blair Waterway & Jul, 1980 & Jun, 1982 \\
\hline \multirow[t]{5}{*}{ Assessment Study } & & Tacoma, WA & & \\
\hline & Duwamish & $\begin{array}{l}\text { Duwamish River } \\
\text { Seattle, WA }\end{array}$ & Aug, 1980 & Jun, 1982 \\
\hline & Hylebos & $\begin{array}{l}\text { Hylebos Waterway } \\
\text { Tacoma, WA }\end{array}$ & Jul, 1980 & Jun, 1982 \\
\hline & Manchester & $\begin{array}{l}\text { Main Basin of Puget Sound } \\
\text { Manchester, WA }\end{array}$ & Jul, 1980 & Jun, 1982 \\
\hline & Milwaukee & $\begin{array}{l}\text { Milwaukee Waterway } \\
\text { Tacoma, WA }\end{array}$ & Jul, 1980 & Jun, 1982 \\
\hline
\end{tabular}



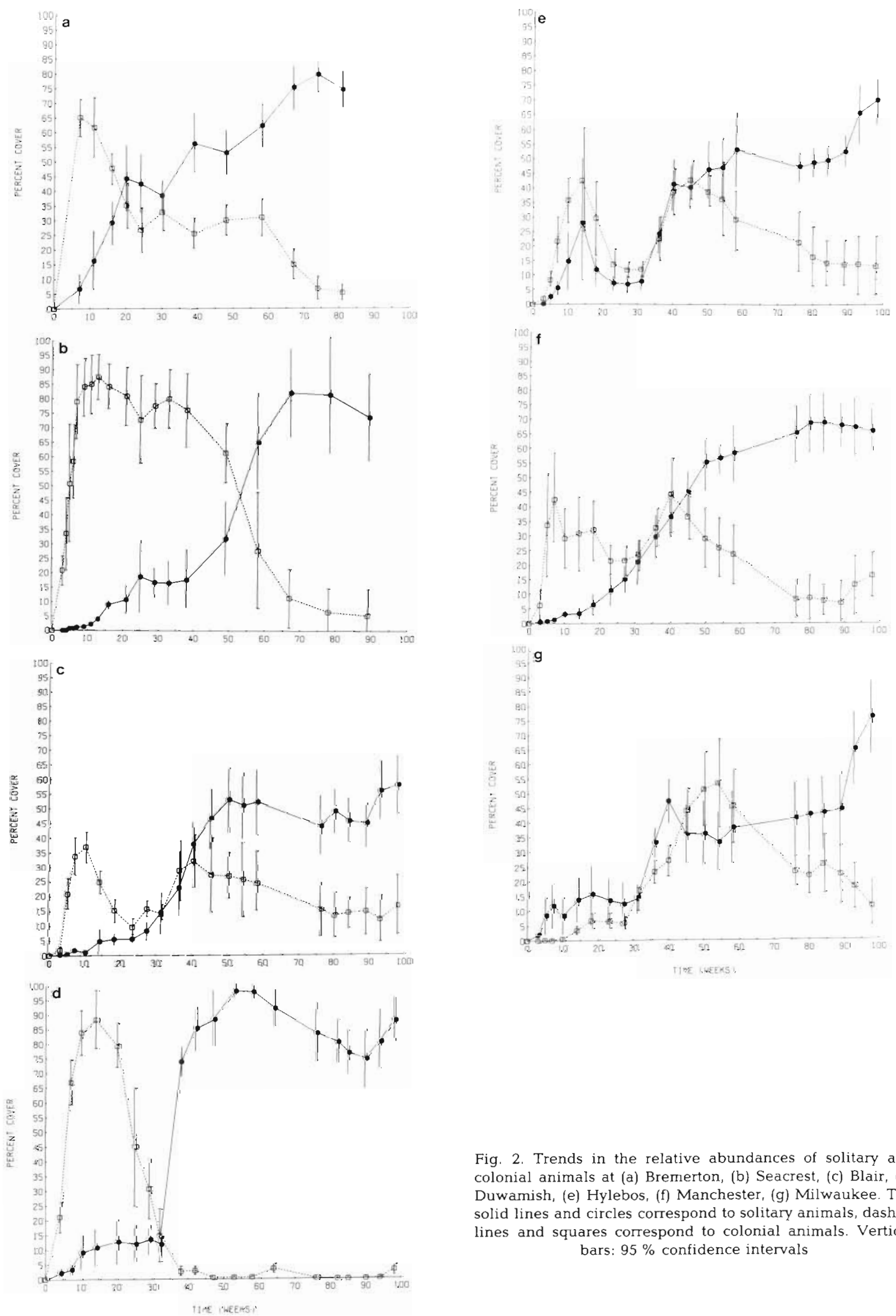

Fig. 2. Trends in the relative abundances of solitary and colonial animals at (a) Bremerton, (b) Seacrest, (c) Blair, (d) Duwamish, (e) Hylebos, (f) Manchester, (g) Milwaukee. The solid lines and circles correspond to solitary animals, dashed lines and squares correspond to colonial animals. Vertical bars: $95 \%$ confidence intervals 
Table 3. Foundation species (>10\% cover, see Greene and Schoener, 1982, in prep.) compositions of the Bremerton, Duwamish River, Manchester, and Tacoma Waterways fouling communities

\begin{tabular}{|c|c|c|c|c|c|c|}
\hline & Bremerton & Blair & Duwamish & Hylebos & Manchester & Milwaukee \\
\hline \multicolumn{7}{|l|}{ SOLITARY ANIMALS } \\
\hline Balanus crenatus & + & $+\cdot$ & $+\cdot$ & $+{ }^{\cdot}$ & $t^{\cdot}$ & $+\cdot$ \\
\hline Corella willmeriana & + & + & & $+{ }^{\cdot}$ & & $+\cdot$ \\
\hline Foliculina sp. & & & & & & + \\
\hline Metridium senile & $++^{*}$ & + & & + & + & \\
\hline Mytilus edulis & + & & & & + & \\
\hline Nereid sp. 1 & + & & & & & \\
\hline Pseudopotamilla occelata & & & & + & + & + \\
\hline Serpula vermicularis & & + & & + & $+\cdot$ & + \\
\hline Serpulid sp. 1 & + & & & & & \\
\hline Styela gibbsii & $+{ }^{\cdot}$ & & & & & \\
\hline \multicolumn{7}{|l|}{ COLONIAL ANIMALS } \\
\hline Botryllus sp. & & & & + & & \\
\hline Bowerbankia gracilis & + & & & & + & + \\
\hline Bryozoan sp. 1 & & + & & + & & + \\
\hline Bryozoan sp. 2 & & & & + & & \\
\hline Bryozoan sp. 3 & + & & & & & \\
\hline Bugula pacifica & & + & & & & + \\
\hline Callopora horrida & & + & & + & & \\
\hline Cryptosula pallasiana & & & & + & & \\
\hline Dendrobeania lichenoides & $+\cdot$ & & & + & & + \\
\hline Diplosoma macdonaldi & + & & & & & \\
\hline Distaplia occidentalis & + & & & & & \\
\hline Hippothoa hyalina & + & + & & & & \\
\hline Hydroid sp. 1 & & + & & + & + & + \\
\hline Leucosolenia sp. & & & & & + & \\
\hline Membranipora spp. & & & + & & + & \\
\hline Obelia sp. & + & & & & + & \\
\hline Reginella nitida & & & & + & + & + \\
\hline Scrupocellaria sp. & & & & & + & \\
\hline Sponge sp. 1 & + & & & & & \\
\hline Sponge spp. (yellow) & + & & & & & + \\
\hline Tunicate sp. 1 & & & & & $+\cdot$ & \\
\hline Tunicate sp. 2 & + & & & & & \\
\hline+ Present in community; $\cdot$ Don & Idation spe & $1>30$ & ver on at l & 1 panel & end of study & \\
\hline
\end{tabular}

are consistent with it. In addition, other investigations (Sutherland and Karlson, 1977; Dean and Hurd, 1980) provide considerable evidence that inhibitory interactions predominate in temperate fouling communities. In light of these investigations, Sousa's (1979, 1980) results from the rocky intertidal, and our own observations, we suggest that inhibition may be a characteristic feature of space-limited systems in general. For an inhibition-type succession to proceed in these systems, space must become available through the damage or death of residents, thereby allowing replacement by other species. In such a species-by-species replacement process, the community composition will gradually shift towards species which live longer or exhibit strong tendencies for self-replacement (Connell and Slatyer, 1977; Greene and Schoener, 1982). In the context of the solitary versus colonial strategy conflict, this model has several important implications: (1) are dis- turbance mechanisms selective in clearing space for subsequent invasion? (2) When does the role of competition betweeen species come into play? (3) What are the important life-history characteristics of the species present?

With regard to the first of these, space availability after the initial colonization period is typically related to some type of disturbance, either biological or physical. In our usage, any process which opens up space is included as a disturbance mechanism (Greene and Schoener, 1982). Predation, the process generally associated with biological disturbance (Dayton, 1971; Dayton and Hessler, 1972), does not appear to be a major mechanism opening up space in Puget Sound fouling communities, although this still needs to be tested adequately with well-controlled field manipulations. In addition to quantifying the effects of predation as a disturbance agent within the community, an 
understanding of the selective nature of predation is equally important in assessing its impact on community development. In a few temperate localities, caging experiments have implicated fish predation with some type of structuring role in fouling community development (Sutherland, 1974; Russ, 1980). In other cases, however, investigators have downplayed the importance of that role (Osman, 1977; Sutherland and Karlson, 1977; Dean and Hurd, 1980). We have observed no visual evidence (e.g. no in situ observations with SCUBA of panels being grazed by fish, no detectable bite or scrape marks seen during censusing) of fish predation on our panels, however, experimentally determining the impact of large, mobile predators in marine communities is often a difficult task (Choat, 1982; Edwards et al., 1982). Despite our tendency to downplay the role of fish predation as well, Russ' (1980) analysis of gut contents indicates that colonial animais may be selectively preyed upon by fish relative to their solitary counterparts. Thus, selective fish predation could provide one viable hypothesis for explaining the patterns we have observed.

In addition to fish, selective invertebrate predators can also have an impact on community development and structure (e.g. Paine, 1966, 1974; Day, 1977; Karlson, 1978; Day and Osman, 1981). The general lack of access to panels by many of the large, mobile invertebrate predators (e.g. asteroids, echinoids, prosobranch gastropods) obviously limits the potential importance of these animals in temperate fouling communities (Karlson, 1978; Harvell, pers. comm.). Nevertheless, small, less mobile invertebrate predators (e.g. amphipods, nemerteans, nudibranchs, polychaetes, pycnogonids, turbellarians) are often quite abundant in these communities, and their roles certainly deserve more attention than has been allotted previously. Selective invertebrate predation could provide another viable hypothesis for explaining the observed patterns should these predators also be found to forage selectively on colonial animals.

At present we have no evidence that predation alone can supply the degree of selective disturbance necessary to explain our observations. A different form of disturbance does appear to be important in Puget Sound fouling communities, however, and this may be a key factor in resolving the solitary versus colonial issue. Rapid seasonal increases, followed by sporadic and/or seasonal mass mortalities and recessions are relatively common features for most of the colonial species found in Puget Sound fouling communities. This can be observed in the trends of relative abundance through time for the vine-like hydroid Obelia sp., the sheet-like tunicate Diplosoma macdonaldi, the sheet-like sponges, and the tree-like tunicates and bryozoans at Bremerton (Figs. 3 to 5). Another notewor-

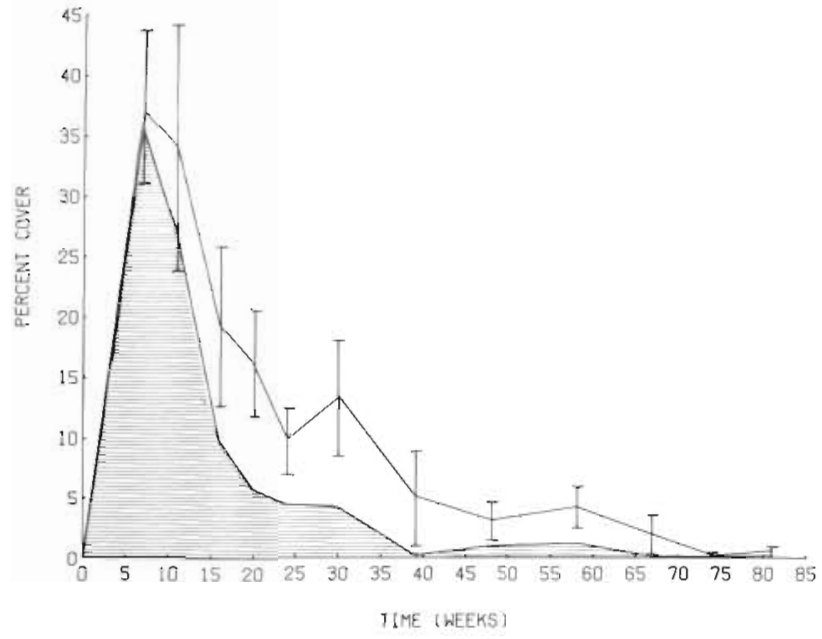

Fig. 3. Trend in relative abundance through time of vine-like colonial animals at Bremerton; hatched area represents hydroid Obelia sp.; open area, a pair of vine-like bryozoans. Vertical bars: $95 \%$ confidence intervals

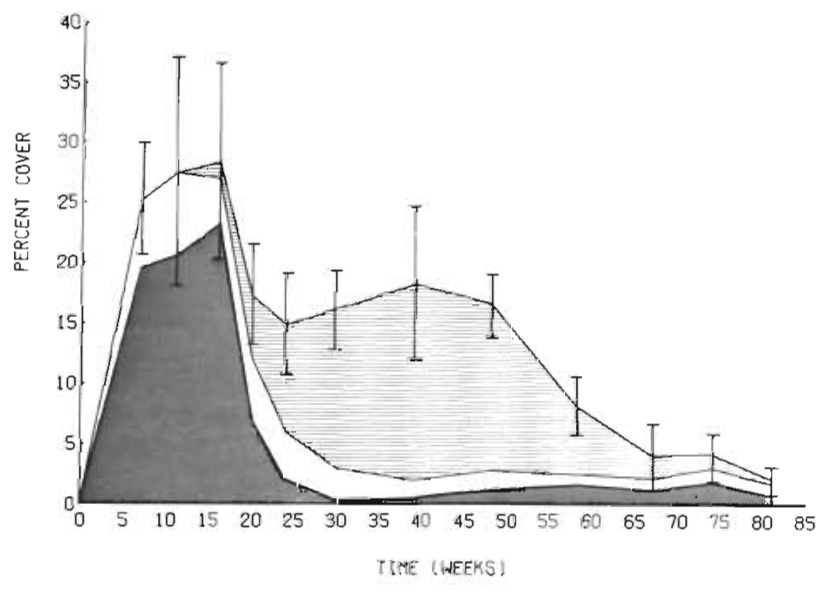

Fig. 4. Trend in relative abundance through time of sheet-like colonial animals at Bremerton; hatched area represents 3 sheet-like sponges; stipled area, the tunicate Diplosoma macdonaldi; open area, a variety of sheet-like bryozoans. Vertical bars: $95 \%$ confidence intervals

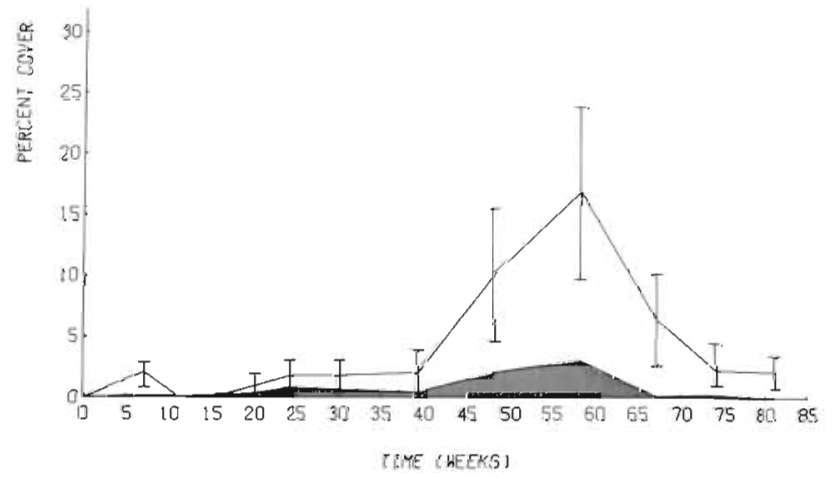

Fig. 5. Trend in relative abundance through time of tree-like colonial animals at Bremerton; stipled area represents 3 treelike bryozoans; open area, a pair of tree-like tunicates. Vertical bars: $95 \%$ confidence intervals 
thy pattern is the transition in morphological dominance from vine-like to sheet-like to tree-like colonial growth forms. With primary space at a premium, this pattern of increasing commitments to defense and maintenance in the areas of substratum attachment follows Jackson's (1979a) predictions exactly. Unlike Jackson's $(1977,1979$ ) results from Jamaica, however, the progression is frequently disturbed, and the relative abundance of colonial animals is gradually dampened as solitary animals preempt more and more space. The frequent disturbances mentioned above, in addition to making space available for invading species, may also have important implications for competition between resident species. This, in turn, leads us to a discussion of the role of competition in the community.

Competition for space is an explicit assumption in Jackson's (1977) arguments for the dominance of colonial animals on marine hard substrata. Typically, in competitive interactions, the existence of a hierarchy is assumed in which one or a few species outcompete all others in the absence of disturbances (Sutherland and Karlson, 1977 and references therein). In cryptic coral reef communities this paradigm does not seem to hold, and investigators have postulated the existence of competitive networks (Jackson and Buss, 1975; Buss and Jackson, 1979; Karlson and Jackson, 1981) and, more recently, the importance of competitive reversals (Jackson, 1979 b; Quinn, 1982; Russ, 1982) to account for the diversity of species observed. These mechanisms seem to apply primarily to interactions among colonial species, and solitary species must seek refuge elsewhere, either by forming dense assemblages or escaping in size (Jackson, 1977).

In Puget Sound fouling communities, however, we hypothesize that disturbances rarely allow competition to proceed to its natural conclusion. Rather, we suspect that space is periodically renewed by the mass mortalities and recessions previously mentioned, and further, that these disturbances may allow longer-lived solitary species the chance they need to escape in size. When this critical size is attained, solitary species have successfully eluded the essentially two-dimensional arena of direct competitive interactions by entering another dimension, the vertical. The consequences involved with adding three-dimensionality to the system are complex and not given due justice in this treatment. Nevertheless, the possibilities for indirect competitive interactions and overtopping strategies are greatly enhanced by adding a third dimension, and some of the consequences are alluded to in Jackson (1979a), Buss (1979b), and Woodin and Jackson (1979). In this regard, vertical growth may ultimately transform solitary animals from inferior direct competitors for space into superior indirect competitors which dras- tically alter the flow regime and/or food availability around them. Such a propositon has many features in common with Connell and Slatyer's (1977) tolerance model, a model in which slower growing, more tolerant species eventually overtop and outcompete the community's earlier residents. Unfortunately, this type of process is purely hypothetical at present, primarily because indirect interactions are much harder to identify in nature and to test experimentally.

Finally, for the results we observed in Puget Sound to be consistent with the predictions of Connell and Slatyer's (1977) inhibition model, the life-history characteristics of solitary and colonial animals must differ in several important features. In an inhibitiontype succession, community composition will shift toward longer-lived species (Connell and Slatyer, 1977) or ones exhibiting strong tendencies for self replacement (Greene and Schoener, 1982). In Puget Sound, most of the important solitary species (e.g. the anemone Metridium senile; the barnacle Balanus crenatus; the mussel Mytilus edulis; the tubiculous polychaetes Pseudopotamilla occelata and Serpula vermicularis; and the solitary tunicate Styela gibbsii) possess the potential longevity to outlive their colonial counterparts. In addition, many solitary species exhibit features which favor self replacement and the subsequent formation of dense, single-species-dominated assemblages (Jackson 1977; Woodin, 1979; Scheltema et al., 1981; Greene and Schoener, 1982). Examples from Puget Sound include the tunicates Corella willmeriana ( $=C$. inflata) and Styela gibbsii. Corella willmeriana, although relatively short-lived, often forms very dense assemblages because it has the capacity to brood its young continuously and release larvae which are competent to settle within a few minutes to a few hours (Morris et al., 1980). Styela gibbsii, on the other hand, seems to be able to perpetuate itself in dense assemblages by gregarious settlement and the ability to filter out other species' larvae while sparing its own (Young, 1982).

\section{Dominance by solitary animals: how general a phenomenon?}

How general an occurrence is the dominance by solitary animals in temperate fouling communities? Since this question has not been adequately studied, we will only approach it by qualifying our remarks with the following caveat: our objective in this paper is not to suggest that solitary animals will tend to dominate in all temperate fouling communities, but rather to emphasize the need for further study before the biogeographical implications can be fully resolved.

In systems where competitive interactions can pro- 
ceed relatively undisturbed, succession may possess many features more in accord with Connell and Slatyer's (1977) tolerance model. In this model, succession leads to a community composed of species most efficient in utilizing space, i.e, better competitors. The Jamaican cryptic reef community seems to be such a system, and colonial animals probably dominate for the reasons Jackson (1977) enumerates.

In systems where disturbance is a common feature, succession may correspond more closely with Connell and Slatyer's (1977) inhibition model. In this model, succession leads to a community dominated by species that are longer-lived or exhibit strong tendencies for self replacement. To decide whether solitary or colonial species will dominate in such a system, the relative space holding abilities of the component species become the key determinants. If solitary animals can maintain their position in the community longer, as in Puget Sound, then they will dominate. Alternatively, if colonies are longer lasting, as for example Schizoporella in New England (Osman, 1977), then colonial animals may dominate. For this type of succession, as Connell and Slatyer (1977) point out, 'possession is eleven points in the law' (Cibber, 1977, p. 121) and the species that last longest eventually dominate the ecological scene.

Acknowledgements. We thank the many people at Friday Harbor Laboratories whose encouragement and expertise greatly improved this manuscript and the ideas behind it. The authors would like to thank especially E. Gallagher, C. D. Harvell, L. Incze, J, B. C. Jackson, S. Lidgard, B. Okamura, K. Sebens, R. L. Self, J. Sherfy, R. Steneck, R. Strathmann, W. H. Wilson, Jr., and C. Young for their personal insights into the problems addressed by this study. We are also grateful to the members of the Bremerton Yacht Club for their assistance and encouragement during the field program. Support for this research was provided by grants from NOAA, NSF, ONR, and Sigma Xi.

\section{LITERATURE CITED}

Boardman, R. S., Cheetham, A. H., Oliver, Jr., W. A., Coats, A. G., Bayer, F. M. (1973). Introducing colonality. In: Boardman, R. S., Cheetham, A. H., Oliver, Jr., W. A. (ed.) Animal colonies, development and function through time. Dowden, Hutchinson and Ross, Stroudsburg, Pennsylvania, p. $v$-ix

Buss, L. W. (1979a). Habitat selection, directional growth, and spatial refuges. In: Larwood, G., Rosen, B. R. (ed.) Biology and systematics of colonial organisms. Academic Press, London and New York, p. 459-497

Buss, L. W. (1979b). Bryozoan overgrowth interactions - the interdependence of competition for space and food. Nature, Lond. 281: $475-477$

Buss, L. W., Jackson, J. B. C. (1979). Competitive networks: nontransitive competitive relationships in cryptic coral reef environments. Am. Nat. 113: 223-234.

Choat, J. H. (1982). Fish feeding and the structure of benthic communities in temperate waters. Ann. Rev. Ecol. Syst. 13: $423-450$

Cibber, C. (1777). Woman's wit (or, the lady in fashion). In: The dramatic works of Colley Cibber, Esq., Vol. 1, J. Rivington, London, p. 99-200 (reprinted, AMS, New York, 1966)

Connell, J. H., Slatyer, R. O. (1977). Mechanisms of succession in natural communities and their role in community stability and organization. Am. Nat. 111: 1119-1144

Day, R. W., (1977). Two contrasting effects of predation on species richness in coral reef habitats. Mar. Biol. 44: 1-5

Day, R. W., Osman, R. W. (1981). Predation by Patiria miniata (Asteroidea) on bryozoans: prey diversity may depend on the mechanism of succession. Oecologia 51: 300-309

Dayton, P. K. (1971). Competition, disturbance and community organization: the provision and subsequent utilization of space in a rocky intertidal community. Ecol. Monogr. 41: 351-389

Dayton, P. K., Hessler, R. R. (1972). Role of biological disturbance in maintaining diversity in the deep sea. Deep Sea Res. 19: 199-208

Dean, T. A., Hurd, L. E. (1980). Development in an estuarine fouling community: the influence of early colonists on later arrivals. Oecologia 46: 295-301

Edwards, D. C., Conover, D. O., Sutter III, F. (1982). Mobile predators and the structure of marine intertidal communities. Ecology 63: 1175-1180

Greene, C. H., Schoener, A. (1982). Succession on marine hard substrata. A fixed lottery, Oecologia 55: 289-297

Greene, C. H., Schoener, A. (in prep.). Multivariate analysis of three-dimensional data in the study of succession in marine fouling communities.

Jackson, J. B. C. (1977). Competition on marine hard substrata: the adaptive significance of solitary and colonial strategies. Am. Nat. 111: 743-767

Jackson, J. B. C. (1979a). Morphological strategies of sessile animals. In: Larwood, G., Rosen, B. R. (ed.) Biology and systematics of colonial organisms. Academic Press, London and New York, p. 499-553

Jackson, J. B. C. (1979b). Overgrowth competition between encrusting cheilostome ectoprocts in a Jamaican cryptic reef environment. J. Anim. Ecol. 48: 805-823

Jackson, J. B. C., Buss, L. W. (1975). Allelopathy and spatial competition among coral reef invertebrates. Proc. natn. Acad. Sci. U.S.A. 72: 5160-5163

Karlson, R. (1978). Predation and space utilization patterns in a marine epifaunal community. J. exp. mar. Biol. Ecol. 31: 225-239

Karlson, R., Jackson, J. B. C. (1981). Competitive networks and community structure: a simulation study. Ecology 62 : $670-678$

Morris, R. H., Abott, D. P., Haderlie, E. C. (1980). Intertidal invertebrates of California. Stanford University Press, Stanford

Osman, R. W. (1977). The establishment and development of a marine epifaunal community. Ecol. Monogr. 47: 37-63

Paine, R. T. (1966). Food web complexity and species diversity. Am. Nat. 100: 65-75

Paine, R. T (1974). Intertidal community structure. Experimental studies on the relationship between a dominant competitor and its principle predator. Oecologia 15 $93-120$

Quinn, J. F. (1982). Competitive hierarchies in benthic communities. Oecologia 54:129-135

Russ, G. R. (1980). Effects of predation by fishes, competition and structural complexity. J. exp. mar. Biol. Ecol. 42: $55-69$ 
Russ, G. R. (1982). Overgrowth in a marine epifaunal community: competitive hierarchies and competitive networks. Oecologia 53: 12-19

Scheltema, R. S., Williams, I. P., Shaw, M. A. (1981). Gregarious settlement by the larvae of Hydroides dianthus (Polychaeta: Serpulidae). Mar. Ecol. Prog. Ser. 5: 69-74

Schoener, A. (1981). Artificial substrates in marine environments. In: Cairns, J. C. (ed.) Use of artificial substrates in aquatic community, structural and functional analyses. Ann Arbor Science Publishers Incorporated, Ann Arbor, Michigan, p. 1-22

Schoener, A., Greene, C. H. (1980). Variability among identical fouling panels in Puget Sound, Washington, U.S.A. In: 5th International Congress on Marine Corrosion and Fouling. Barcelona, Spain, p. 213-224

Schoener, A., Greene, C. H. (1981). Comparison between destructive and nondestructive sampling of sessile epibenthic organisms. Limnol. Oceanogr. 26: 770-774

Schoener, A., Schoener, T. W. (1981). The dynamics of the species-area relation in marine fouling systems: biological correlates of changes in the species area slope. Am. Nat. 118: 339-360

Sousa, W. P. (1979). Experimental investigations of disturbance and ecological succession in a rocky intertidal algal community. Ecol. Monogr. 49: 227-254
Sousa, W. P. (1980). The responses of a community to disturbance: the importance of successional age and species life histories. Oecologia 45: 72-81

Sutherland, J. P. (1974). Multiple stable points in natural communities. Am. Nat. 108: 859-873

Sutherland, J. P. (1978). Functional roles of Schizoporella and Styela in the fouling community at Beaufort, North Carolina. Ecology 59: 257-264

Sutherland, J. P., Karlson, R. H. (1973). Succession and seasonal progression in the fouling community at Beaufort, North Carolina. In: 3rd International Congress on Marine Corrosion and Fouling. Northwestern University Press, Evanston, Illinois, p. 906-929

Sutherland, J. P., Karlson, R. H. (1977). Development and stability of the fouling community at Beaufort, North Carolina. Ecol. Monogr. 47: 425-446

Woodin, S. A. (1979). Settlement phenomena: the significance of functional groups. In: Stancyk, S. E. (ed.) Reproductive ecology of marine invertebrates. University of South Carolina Press, Columbia, South Carolina, p. 99-106

Woodin, S. A., Jackson, J. B. C. (1979). Interphyletic competition between marine benthos. Am. Zool. 19: 1029-1043

Young, C. M. (1982), Larval behavior, predation and early post-settling mortality as determinants of spatial distribution in subtidal solitary ascidians of the San Juan Islands, Washington. Ph. D. thesis, University of Alberta

This paper was submitted to the editor; it was accepted for printing on June 18, 1983 